\title{
REQUIREMENTS FOR PAVEMENT BASE LAYERS WITH UNBOUND GRANULAR MATERIAL
}

\author{
Silvia CÁPAYOVÁ ${ }^{*}$, Zuzana ŠTEFUNKOVÁ², Stanislav UNČík ${ }^{2}$, Andrea ZUZULOVÁ
}

\begin{abstract}
Pavement structures, layers, and parameters must meet the strict requirements of applicable standards and regulations. The thickness of layers and the choice of materials depend on the factors involved, i.e., the traffic load and climatic factors (changes in temperature, water, rain, snow); they are also dependent on the geological environment at the road construction site and the parameters and properties of the embankment (the subgrade of the pavement). In some cases, the capacity of the existing transport infrastructure is on the edge of sustainability. The increase in the traffic load and the use of lower-class roads by freight transport, together with insufficient maintenance, has resulted in a deterioration of road conditions, thereby causing many deficiencies and failures.

The required serviceability and operational performance of roads can be ensured by the choice of suitable quality materials and technological construction processes. Technologies that are environmentally acceptable and economically efficient should be preferred.
\end{abstract}

\section{Address}

1 Dept. of Transportation Engineering, Faculty of Civil Engineering, Slovak University of Technology in Bratislava, Slovakia

2 Dept. of Material Engineering, Faculty of Civil Engineering, Slovak University of Technology in Bratislava, Slovakia

* Corresponding author: silvia.capayova@stuba.sk

\section{Key words}

- Pavement structure,

- Unbound granular mixture,

- Laboratory tests,

- Modified Proctor Test,

- Immediate bearing index (IBI).

\section{INTRODUCTION}

For the design of a pavement structure, we have to consider standard or non-standard conditions, i.e., a territory with a high groundwater level, or unsuitable or conditionally suitable soil and rock, including those with long-term mining activity. In the last case, these include areas with underground mining, a large amount of which are on the territory of the former Czechoslovakia. Designing pavement structures in such often unstable regions is interesting and not always simple (Cihlářová et al., 2013; Moravčík et al., 2016). Another essential factor is the maintenance of a road, which also contributes to its conditions. One problem in the design of a pavement structure may involve assuming the traffic load for the design period. The growth in traffic over recent decades is in some cases incompatible with forecasting models/calculations that use prospective growth ratios. Many pavements must carry n-times higher loads than those that have been designed. On 31 May 2019 (Ministry of the Interior of the Slovak Re- public, 2019), there were 3,248,330 vehicles registered in Slovakia, a year-on-year increase of $3.5 \%$. On 31 December 2008, a total of $2,158,181$ vehicles were registered. That is an increase of $48 \%$ over the last ten years!

The main courses of a pavement are the base layers, the number (2-3) of which depend on the traffic load and the material used. They ensure load transfer from vehicle axles and reduce stress to a permissible level. The materials in the base layers must have sufficient flexural tensile strength and resistance to permanent deformation as well as resistance to frost. The following technologies can be used:

- unbound mixtures: mechanically reinforced aggregate (in Slovak: mechanicky spevnené kamenivo (MSK*), crushed gravel (in Slovak: štrkodrvina $\left(\breve{S} \mathrm{D}^{*}\right)$;

*Note: This mixture designation is in accordance with related STN and EN standards. According to the technical regulation (TKP 5, 2014), the designation UM MSK (UM SD) is used, where UM means Unbound Mixture. 
- hydraulically bound mixtures: most often, a cement-bound granular mixture (CBGM); alternatively, a hydraulic road binder-bound granular mixture (HBBM), and

- asphalt bound mixtures: asphalt concrete (AC).

This paper will deal with asphalt pavements for which other requirements apply versus cement concrete pavements. A typical flexible pavement structure is shown in Fig. 1. The pavement structure must be designed in accordance with STN 73 6114, Pavement of Roads, Basic Provision for Structural Design, and the technical regulation TP 033, Design of Flexible and Semi-Rigid Pavements. The materials must comply with the requirements of Act No. 133/2013, On Construction Products and on the Amendment of Certain Acts. For the design of the composition and parameters of unbound mixtures, the following standards and technical regulations are in force:

- STN 736126 Road Construction. Unbound Courses (2011),

- STN EN 13285 Unbound Mixtures - Specification (2011, 2019),

- TKP 5/2014 Base Layers,

- KLK 1/2012 Catalog Sheets of Aggregates + Addendum No. $1 / 2016$ to KLK $1 / 2012$.

The relevant STN, STN EN product and testing standards, technical regulations, technical quality conditions, and catalog sheets are valid for the verification of the properties of road construction materials.
The use of unbound and bound mixtures in the base courses of a pavement, depending on the traffic load class (TLC) (Table 1), is shown in Table 2.

\section{UNBOUND “MECHANICALLY REINFORCED AGGREGATE" MIXTURES}

In different countries, mixtures of unbound aggregates are distributed according to the site requirements. It is possible to use a standard unbound mixture (ŠD) or a mechanically reinforced aggregate mixture (MSK), which is the best quality unbound mixture. Compared to the standard mixture, it is only used in the base layers of a pavement structure. The maximum quality of the mixture is ensured by the quality of the aggregate used and the production in a stationary or mobile plant. High-capacity vehicles with protection against drying of the mixture are used for the transport. A finisher with an automatic levelling device (TLC I-III) or other suitable mechanisms for lower traffic load classes is used for laying the mixture. The basic parameters of the standard and MSK mixtures, according to the technical regulation TKP 5, are in Table 3 .

The selection of such a material in the base layers is rare in our country. When choosing a particular mixture, its economic efficiency is also decisive. This results from the composition of the mixture. i.e.,

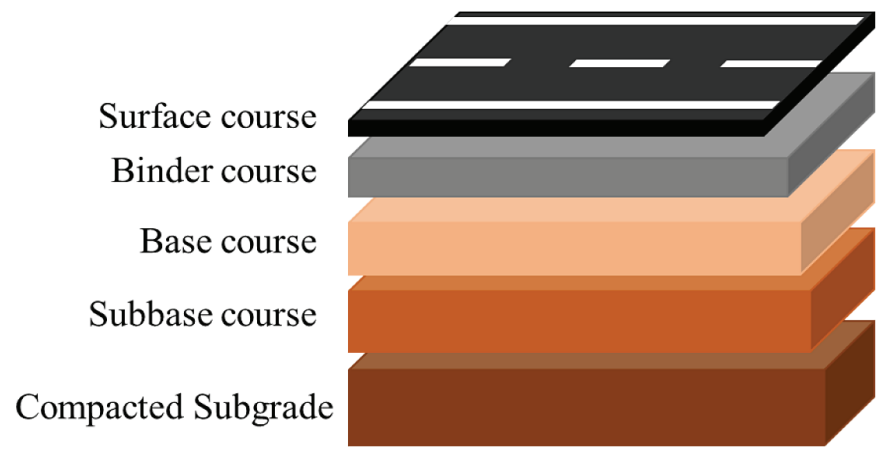

Fig. 1 Flexible pavement structure

Tab. 2 Use of mixtures in the base course (TKP 5, 2014)
Tab. 1 Distribution of roads according to traffic load class (STN 73 6114)

\begin{tabular}{|c|c|}
\hline $\begin{array}{c}\text { NUMBER OF FREIGHT VEHICLES (FV) IN } \\
\text { BOTH DIRECTIONS (FV per 24 hours) }\end{array}$ & $\begin{array}{c}\text { TRAFFIC } \\
\text { LOAD } \\
\text { CLASS }\end{array}$ \\
\hline$>3500$ & I \\
\hline $1501-3500$ & II \\
\hline $501-1500$ & III \\
\hline $101-500$ & IV \\
\hline $15-100$ & V \\
\hline$<15$ & VI \\
\hline
\end{tabular}

\begin{tabular}{|c|c|c|c|c|}
\hline \multirow{2}{*}{\multicolumn{2}{|c|}{ TYPE OF MIXTURE }} & \multicolumn{3}{|c|}{ THE HIGHEST TRAFFIC LOAD CLASS ALLOWED } \\
\hline & & UPPE & JRSE & BOTTOM BASE COURSE \\
\hline \multicolumn{2}{|c|}{$\mathrm{UM} \mathrm{MSK}^{1)}$} & \multicolumn{2}{|c|}{ IV - VI } & $\mathrm{I}-\mathrm{VI}$ \\
\hline \multicolumn{2}{|c|}{ UM ŠD ${ }^{2)}$} & \multicolumn{2}{|c|}{$\mathrm{V}-\mathrm{VI}$} & IV - VI \\
\hline \multicolumn{2}{|c|}{$\mathrm{CBGM} \mathrm{C}_{8 / 10}, \mathrm{CBGM} \mathrm{C}_{6 / 8}, \mathrm{CBGM} \mathrm{C}_{5 / 6}{ }^{*}$} & \multicolumn{2}{|c|}{ I -III } & I -VI \\
\hline \multicolumn{2}{|c|}{$\mathrm{CBGM} \mathrm{C}_{3 / 4}{ }^{*}$} & \multicolumn{2}{|c|}{ IV -VI } & I -VI \\
\hline $\mathrm{AC} 16, \mathrm{I}^{3)}$ & $\mathrm{AC} 16, \mathrm{II}^{4)}$ & I -III & IV -VI & \\
\hline $\mathrm{AC} 22, \mathrm{I}^{3)}$ & $\mathrm{AC} 22, \mathrm{II}^{4)}$ & I -III & IV -VI & \\
\hline AC $32, I^{3)}$ & $\mathrm{AC} 32, \mathrm{II}^{4)}$ & I -III & IV -VI & \\
\hline
\end{tabular}

1) Mechanically reinforced aggregate

2) Crushed gravel

3) Asphalt concrete for the first quality class (TLC I -III)

4) Asphalt concrete for the second quality class (TLC IV -VI)

* Alternatively, HBBM mixture 
Tab. 3 Required parameters for unbound mixtures in the base layers of the pavement structure (TKP 5, 2014)

\begin{tabular}{|c|c|c|c|}
\hline & \multirow{2}{*}{\multicolumn{2}{|c|}{ MIXTURE }} \\
\hline & & & \\
\hline \multicolumn{2}{|c|}{ PARAMETER } & UM MSK & UM ŠD \\
\hline \multicolumn{2}{|c|}{ Traffic load class } & I -VI & IV -VI \\
\hline \multicolumn{2}{|c|}{ Fine aggregate } & $0 / 2 ; 0 / 4 ; 0 / 6.3$ & - \\
\hline \multicolumn{2}{|c|}{ Coarse aggregate } & $\begin{array}{c}2 / 4 ; 4 / 8 ; 8 / 16 ; 8 / 22.4 ; 11 / 22.4 ; 16 / 22.4 ; 16 / 31.5 \\
31.5 / 45 ; 16 / 45\end{array}$ & - \\
\hline \multicolumn{2}{|c|}{ All-in aggregate } & - & $0 / 22.4 ; 0 / 31.5 ; 0 / 45 ; 0 / 63$ \\
\hline \multicolumn{2}{|c|}{ Grading } & $\mathrm{G}_{\mathrm{B}}$ & $\mathrm{G}_{\mathrm{C}}$ \\
\hline \multirow{4}{*}{ Percent passing } & 2D & - & - \\
\hline & 1.4D & 100 & 100 \\
\hline & D & $90-99$ & $85-99$ \\
\hline & Category & $\mathrm{OC}_{90}$ & $\mathrm{OC}_{85}$ \\
\hline \multirow{2}{*}{$\begin{array}{l}\text { Percent passing through } \\
0.063 \mathrm{~mm} \text { sieve }\end{array}$} & $\max$. UF & $\mathrm{UF}_{7}$ & $\mathrm{UF}_{5}$ \\
\hline & $\min . \mathbf{L F}$ & $\mathrm{LF}_{4}$ & $\mathrm{LF}_{2}$ \\
\hline \multicolumn{2}{|c|}{ Required bearing capacity IBI (\%) } & 100 & - \\
\hline \multicolumn{2}{|c|}{$\begin{array}{c}\text { Subbase course } \\
{\text { Deformation modulus } \mathrm{E}_{\text {def } 2}(\mathrm{Mpa})}\end{array}$} & $\begin{array}{c}\text { UM ŠD } \\
120\end{array}$ & $\begin{array}{c}\text { UM ŠD C } \\
70 \\
\text { deklarovaná }\end{array}$ \\
\hline
\end{tabular}

the type and properties of the material, its availability, its processing; the mixing, transport, laying and compaction of the mixture, and the thickness of the layer. In the case of CBGM mixtures, it is also necessary to consider the formation of joints, the subsequent treatment of the finished layer and the treatment of reflective cracks during the life cycle of the pavement. The advantage of MSK mixtures is the possibility of laying another structural layer on the second day. However, a greater thickness of the layer and therefore a greater volume of material for transport is required.

The STN EN 13242 + A1 (2008) standard makes it possible to use natural, artificial, or recycled aggregates in MSK mixtures. In this case, one possibility is the use of unbound or hydraulic bounded material from a demolished pavement structure. On the other hand, the

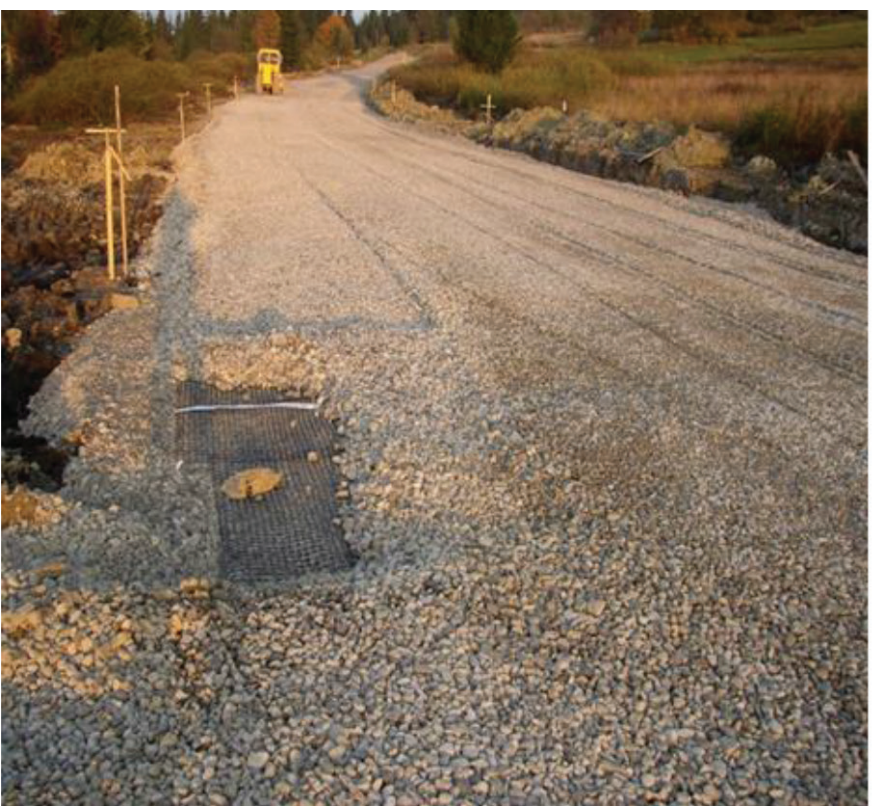

increasing volume of the demolition and decontamination of building structures brings with it the problem of the environmentally acceptable utilization of building rubble. The largest volume of building structures and thus the largest share of demolition waste is formed by brick masonry and concrete. Recycled aggregates for pavement structures can be obtained by the sorting and subsequent treatment of the concrete, i.e., by crushing and sorting it into fractions. However, certain specific properties must be taken into account for recycled aggregates. These are due to the fact that the individual grains are either grains of the original aggregate, which are partially or completely covered with cement, or are made of cementitious mortar or agglomerates of grains bounded with cementitious mortar. Small recycled fractions contain a large proportion of cement, which is gener-

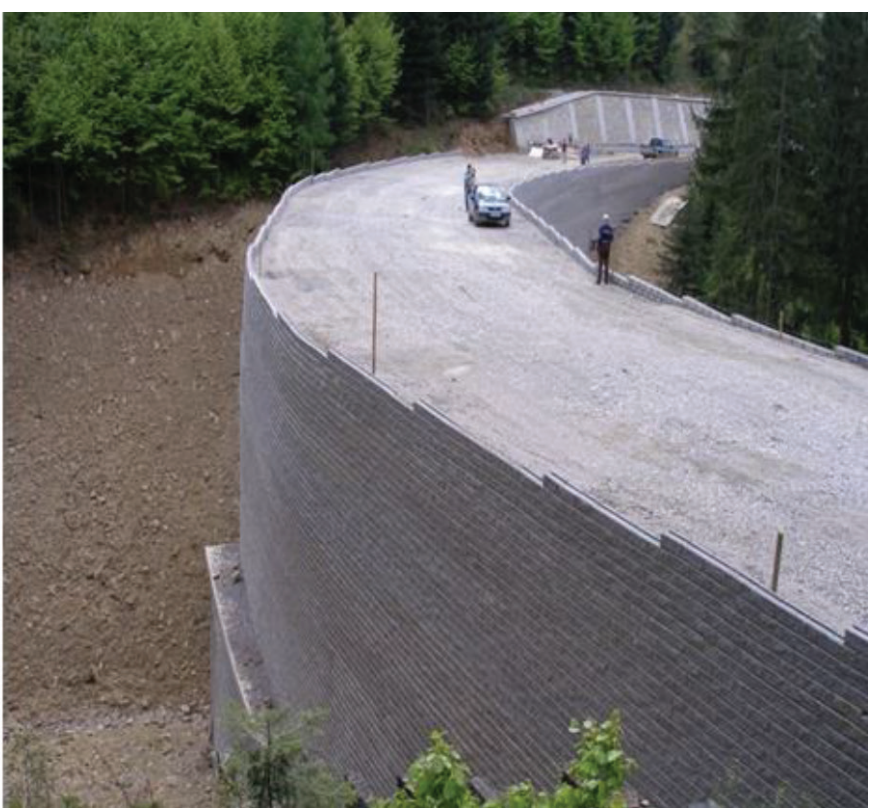

Fig. 2 Road II/520 -Nová Bystrica-Oravská Lesná section (photo: K. Bacova) 


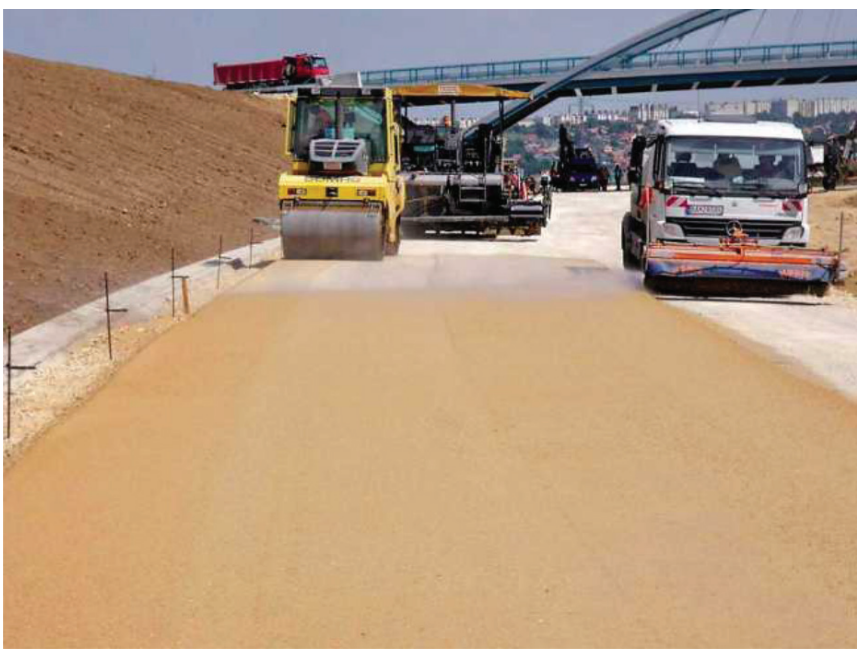

Fig. 3 Rl Expressway - compacting the mixture with a set of rollers (photo: J. Kollar)

ally highly carbonated and, in some cases, chemically contaminated. In addition, they may contain contaminants that entered the material during demolition work. The quality of recycled aggregates is also significantly influenced by the quality of the original concrete as well as the preparation technology for recycling them (Chandra, 2004; Qiu-Yi, 2005; Hirokazu et al., 2005; Stehlík, 2015).

Despite the fact that MSK mixtures in Slovakia have not yet been used to a very large extent, a number of important constructions demonstrate their relevance. For example, in 2004, they were used to relocate Road II/520 on the Nová Bystrica - Oravská Lesná section (Fig. 2). In 2012, MSK was used in the pavement structure on a section of the important R1 expressway, i.e., the Beladice - Tekovské Nemce section with a thickness of $240 \mathrm{~mm}$ and a gradation of $0 / 31.5 \mathrm{G}_{\mathrm{B}}$ (Fig. 3 - 5). The length of that section is approximately 14.3 $\mathrm{km}$. The aggregates, which were a type of limestone, were from the Pohranice (SK) quarry. The mixture was laid in two layers until the desired thickness was achieved. In a compaction experiment, the first layer was optimally compacted after four travels through vibratory rollers and after five travels on the second layer.

\section{DESIGN OF AN AGGREGATE MIXTURE FOR HIGHER TRAFFIC LOAD CLASSES}

The design of an MSK type unbound mixture that is suitable for a pavement structure for higher traffic load classes I-III (Table 1) must meet the requirements of the above technical regulations. The design of a particular type of mixture is followed by optimization. The aggregates must form a solid framework. The grains must be interlocked and the space between them filled with smaller grains. Materials graded "poor" with a narrow range of individual grain sizes are unsuitable. Such a mixture is unstable and cannot be compacted to the required degree. The overall behaviour of the mixture in a pavement structure is affected by its moisture and fine particle properties. A small amount of water prevents the necessary arrangement of the aggregate grains and makes compaction complicated. A large amount of water prevents compaction due to pore filling between grains, which reduces pore size. Moreover, water cannot escape from the pores. Therefore in practice, it is necessary to know the socalled optimum moisture $\mathrm{w}_{\mathrm{opt}}(\%)$ of the mixture at which the maximum bulk density $\rho_{\mathrm{d} \text { max }}\left(\mathrm{kg} / \mathrm{m}^{3}\right)$ is reached. Fine particles smaller than $0.063 \mathrm{~mm}$ are important for processing the mixture at a certain moisture level and thereby ensuring its mechanical stability. They

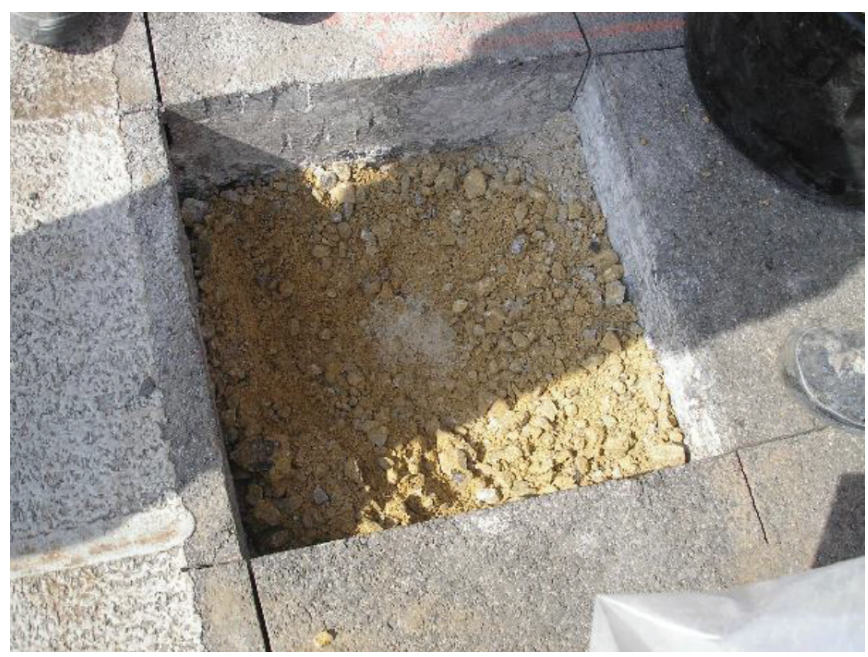

Fig. 4 The MSK 0/31.5 mixture under a hydraulically bound mixture (photo: J. Kollar)

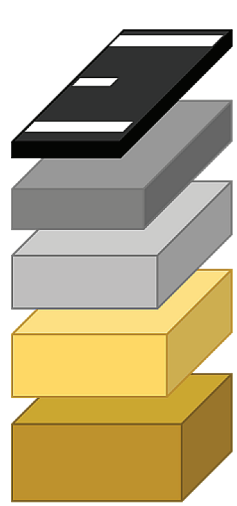

Stone mastic asphalt

SMA 11; PMB 45/80-75

$40 \mathrm{~mm}$

Asphalt concrete

AC 22 L; PMB 45/80-55

$70 \mathrm{~mm}$

High modulus asphalt concrete HMAC 22; PMB 10/40-65

$90 \mathrm{~mm}$

Mechanically reinforced aggregates

MSK $31.5 \mathrm{G}_{\mathrm{B}}$

$240 \mathrm{~mm}$

Crushed gravel

ŠD $31.5(45) \mathrm{G}_{\mathrm{C}}$

$200 \mathrm{~mm}$

Total $640 \mathrm{~mm}$

Fig. 5 Pavement structure - R1 expressway, Beladice - Tekovské Nemce section

should be inert and free from clay particles whose plastic properties may affect the internal friction and bearing capacity of the layer. The proportion of the individual components of the mixture results in the subsequent resistance of the layer to failure and deformation.

In our case, we determined how moisture affects the bearing capacity of the entire base layer of this unbound mixture. The reason for this was that our knowledge and practical experience point to the fact that, even though the results of the laboratory tests of the mixture were in accordance with the technical regulations, the immediate bearing index (IBI) is sometimes not achieved at the construction site. In the experimental part, we tried to solve this problem, i.e., we determined the values of the maximum bulk density and optimal moisture, and then we defined the IBI value at this optimal moisture and also at a moisture of $\pm 1 \%$.

The proposed MSK 0/31.5 mixture consists of four aggregate fractions from the Sološnica (SK) quarry, i.e., 0/4, 4/8, 8/16 and $16 / 32$. The basic properties of the aggregates, which have been determined and are in accordance with the (KLK 1/2012, 2012), are shown in Table 3; the granularity of the fractions is in Fig. 6.

The granularity curve of the mixture shoud be designed to comply with the relevant upper and lower limits (Fig. 7). The percentages of the individual aggregate fractions are shown in Table 4. The technical regulation (TKP 5, 2014) also prescribes an undersize $(0.063 \mathrm{~mm}$ sieve) of $4-7 \%$ and an oversize (D sieve) of $90-99 \%$. The proposed mixture fulfilled this requirement. The result is a mixture designed 
Tab. 3 Properties of the aggregates used

\begin{tabular}{|c|c|c|c|c|}
\hline \multirow{2}{*}{ MAIN PROPERTIES } & \multicolumn{4}{|c|}{ AGGREGATE FRACTION } \\
\hline & $0 / 4$ & $4 / 8$ & $8 / 16$ & $16 / 32$ \\
\hline Fines content & $\mathrm{f}_{10}$ & \multicolumn{3}{|c|}{$\mathrm{f}_{2}$} \\
\hline Grading & $\mathrm{G}_{\mathrm{F}} 85$ & \multicolumn{3}{|c|}{$\mathrm{G}_{\mathrm{C}} 85-15$} \\
\hline Shape index & - & \multicolumn{3}{|c|}{$\mathrm{Sl}_{20}$} \\
\hline Flakiness index & - & \multicolumn{3}{|c|}{$\mathrm{Fl}_{20}$} \\
\hline Water absorption & $\mathrm{WA}_{24} 2$ & \multicolumn{3}{|c|}{$\mathrm{WA}_{24} 1$} \\
\hline Particle density $\left[\mathrm{Mg} / \mathrm{m}^{3}\right]$ & 2.72 & \multicolumn{3}{|c|}{2.75} \\
\hline Resistance to fragmentation & - & \multicolumn{2}{|c|}{$\mathrm{LA}_{20}$} & - \\
\hline Resistance to wear (micro-Deval) & - & \multicolumn{2}{|c|}{$\mathrm{M}_{\mathrm{DE}} 15$} & - \\
\hline Resistance to freezing and thawing & - & \multicolumn{2}{|c|}{$\mathrm{F}_{1}$} & - \\
\hline Resistance to magnesium sulfate & - & - & $\mathrm{MS}_{18}$ & - \\
\hline Petrographic description & \multicolumn{4}{|c|}{ Paleobasalt (melaphyr) } \\
\hline Total sulfur content & \multicolumn{4}{|c|}{$\mathrm{S}_{1}$} \\
\hline
\end{tabular}

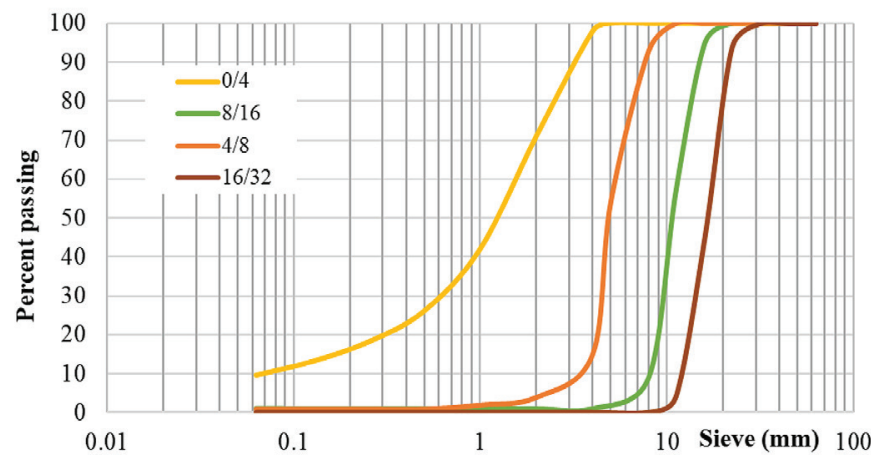

Fig. 6 Granularity curves of aggregate fractions

Tab. 4 The percentage of aggregate fractions in the mixture

\begin{tabular}{|c|c|c|}
\hline \multicolumn{2}{|c|}{ FRACTION } & PERCENTAGE IN THE MIXTURE \\
\hline Fine aggregate & $0 / 4$ & $42 \%$ \\
\hline \multirow{3}{*}{ Course aggregate } & $4 / 8$ & $10 \%$ \\
\cline { 2 - 3 } & $8 / 16$ & $18 \%$ \\
\cline { 2 - 3 } & $16 / 32$ & $30 \%$ \\
\hline
\end{tabular}

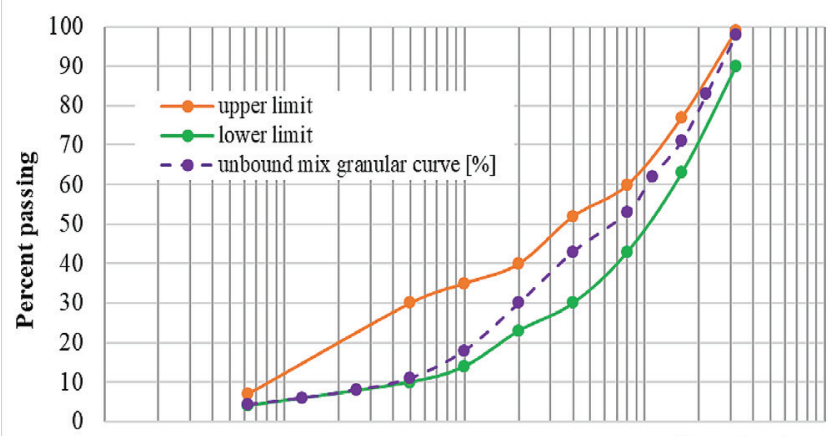

Fig. 7 Granularity curve of MSK 0/31.5 mixture in accordance with the EN standards, MSK $0 / 31.5 \mathrm{G}_{\mathrm{B}}$, an undersize value of $4.3 \%$, and an oversize value of $98 \%$.

The quality control of the mixture produced is verified by its moisture (STN EN 1097-5), granularity (STN EN 933-1), density (STN EN 13286-2), and the immediate bearing index (IBI) (STN EN 13286-47).

\subsection{Laboratory compaction tests}

In accordance with the applicable standards (STN EN 13 2861, 2004), (STN EN 13 286-2, 2013) and technical regulations (KLK 1/2012), (TKP 5, 2014), compatibility is determined by the Modified Proctor Test (MP) for MSK mixtures; the whole aggregate sample is compacted in 5 layers with 56 evenly distributed blows on each layer from a $4.5 \mathrm{~kg}$ rammer with a free fall of $457 \mathrm{~mm}$ (Fig. 8 and 9 (Červená, 2018)). This test (for soil, aggregates, aggregate mixes) is of great importance and is widely used in the construction of roads, highways, earthfill dams, earth filling, airports, etc. The aim is to determine the compaction of different types of aggregates and the properties of the aggregates with changes in the moisture content and the relationship between the dry density and moisture content (Table 5, Fig. 10 (Červená, 2018)).

The maximum dry density was $\rho_{\mathrm{d} \text { max }}=2.280 \mathrm{~g} / \mathrm{cm}^{3}$, and the optimum moisture content was $\mathrm{w}_{\text {opt }}=4.6 \%$.

Tab 5 Results of MP compaction test

\begin{tabular}{|c|c|c|}
\hline NO. & $\begin{array}{c}\text { MOISTURE [\%] } \\
\text { (STN EN 1097-5) }\end{array}$ & $\begin{array}{c}\text { DRY DENSITY } \\
{\left[\mathbf{g . c m}^{-3}\right]}\end{array}$ \\
\hline 1 & 2.8 & 2.137 \\
\hline 2 & 3.2 & 2.211 \\
\hline 3 & 3.8 & 2.245 \\
\hline 4 & $\mathbf{4 . 6}$ & $\mathbf{2 . 2 8 0}$ \\
\hline 5 & 5.1 & 2.229 \\
\hline
\end{tabular}



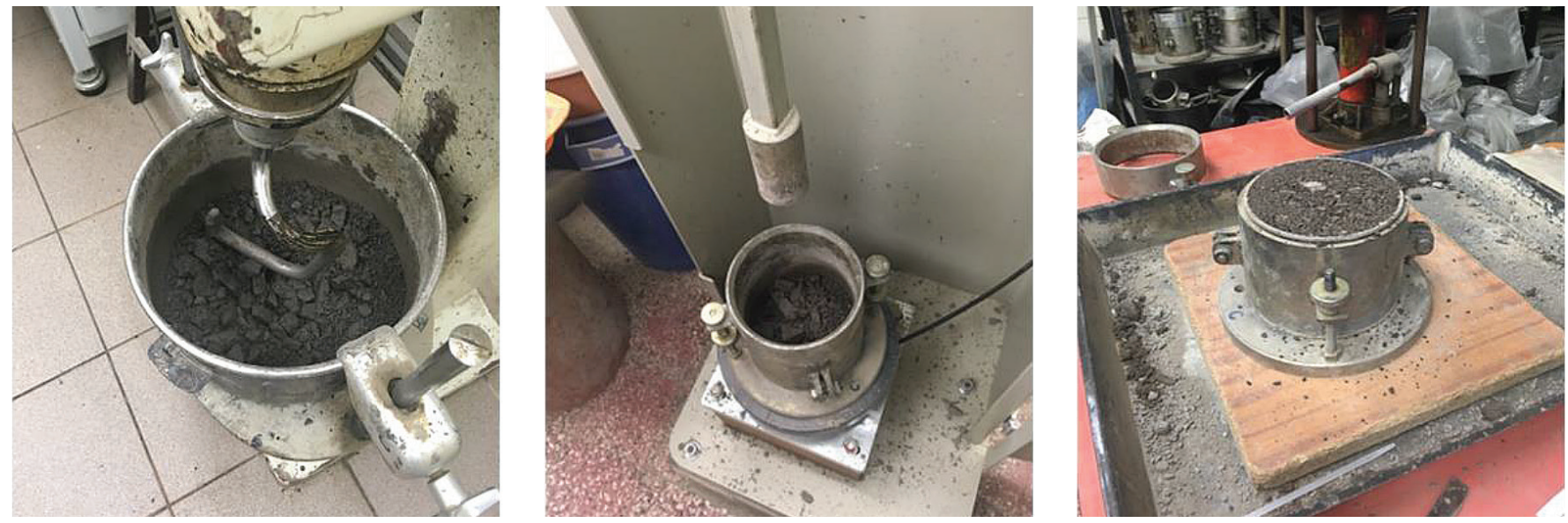

Fig. 8 Compatibility test - laboratory procedure

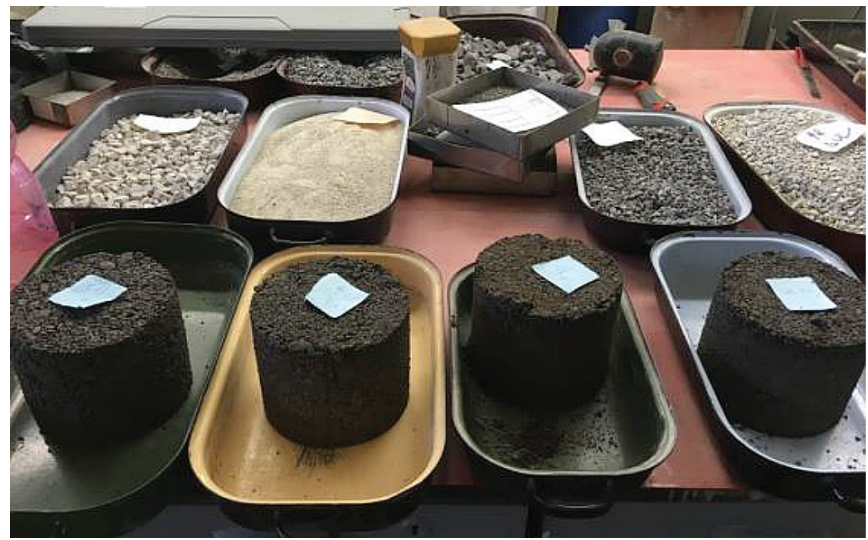

Fig 9. Test samples with different moisture contents ready for drying

\section{$3.2 \mathrm{Immediate}$ bearing index (IBI)}

The IBI test follows the compaction test $\left(\rho_{\mathrm{d}, \max }, \mathrm{w}_{\mathrm{opt}}\right)$ and is a variant of the California Bearing Ratio (CBR) test; the CBR test is carried out immediately without a surcharge (STN EN 13286-47, 2012). The immediate bearing capacity is always determined after the test specimen has been compacted. The test was carried out (Fig. 11 (Červená, 2018)) and evaluated (Fig. 12 (Červená, 2018)) according to the conditions defined in the mentioned standard. In addition, the IBI value was also determined for the optimum moisture of $\pm 1 \%$. Subsequently, the $\mathrm{IBI}_{2.5}$ and $\mathrm{IBI}_{5.0}(\%)$ values (Formula 1) and the $\mathrm{IBI}_{2.5} \geq \mathrm{IBI}_{5.0}$ conditions were calculated from the penetration determined $(\mathrm{mm})$ and the load applied $(\mathrm{kN})$.

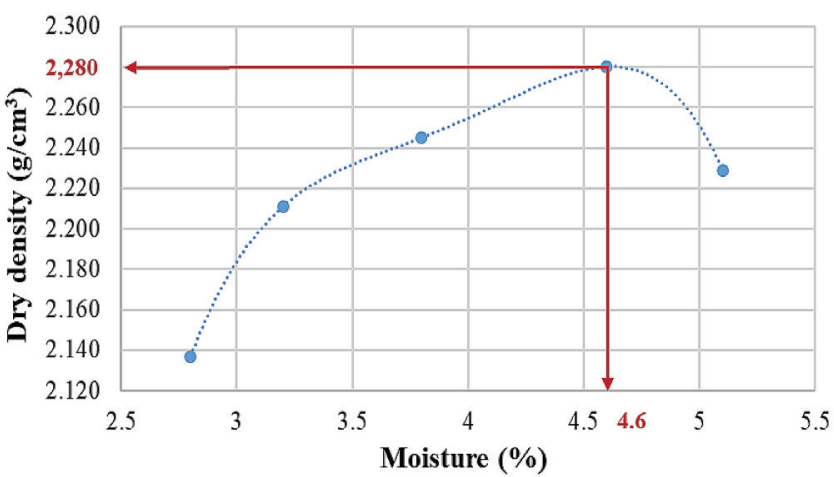

Fig. 10 Compaction curve

$$
\mathrm{IBI}_{2.5(5.0)}=\frac{\mathrm{P}_{2.5(5.0)}}{\mathrm{P}_{2.5(5.0)}^{\prime}} \cdot 100[\%]
$$

where:

$\mathrm{IBI}_{2.5(5.0)}$ - immediate bearing index at a penetration level of $2.5(5.0)$ $\mathrm{mm}[\%]$,

$\mathrm{P}_{25(5.0)}-\quad$ load applied at a penetration level of $2.5(5.0) \mathrm{mm}[\mathrm{kN}]$, $\mathrm{P}_{2.5(5.0)}^{\prime}-$ standard load at a penetration level of $2.5(5.0) \mathrm{mm}[\mathrm{kN}]$.

The larger values of $\mathrm{IBI}_{2.5}$ and $\mathrm{IBI}_{5.0}$ are the results of the test.

For all three cases, the results were $\mathrm{IBI}_{5.0}$; the total final value was $\mathrm{IBI}_{5.0}=135 \%$. According to the standard (STN EN 13286-47, 2012) and technical regulation (TKP 5, 2014), the minimal required IBI value is $100 \%$ (Table 3 ).
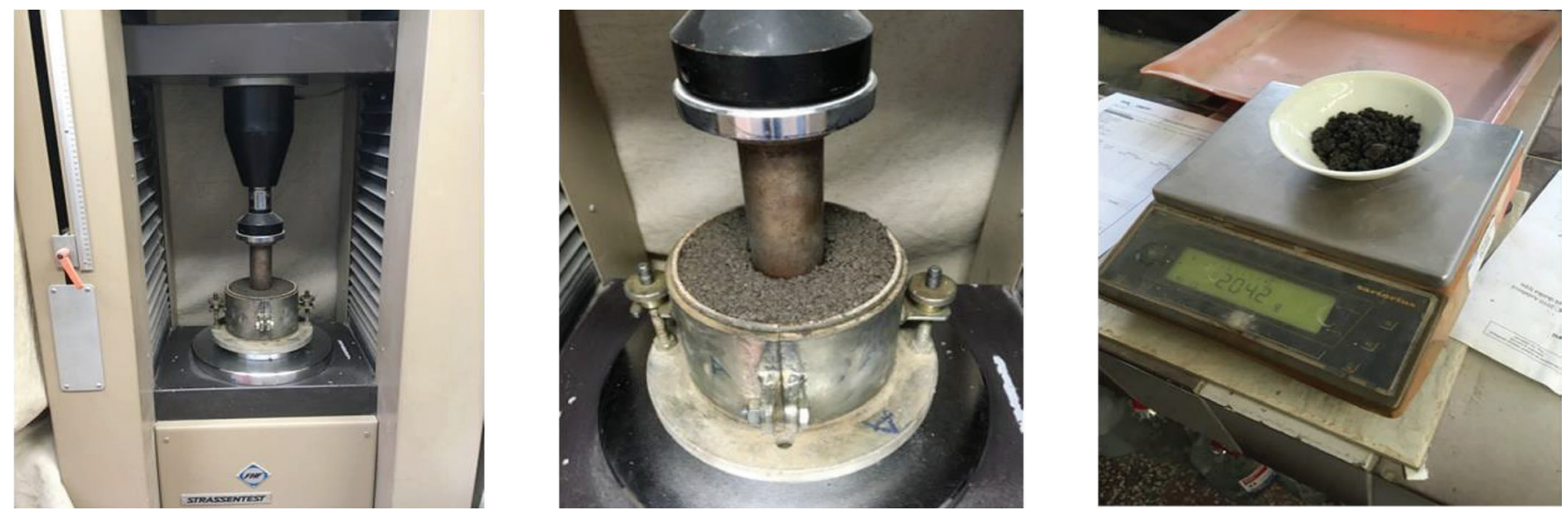

Fig. 11 Immediate bearing index - laboratory procedure 


\begin{tabular}{|c|c|c|c|c|c|}
\hline \multirow{2}{*}{$\begin{array}{c}\text { Penetration } \\
{[\mathbf{m m}]}\end{array}$} & \multirow{2}{*}{$\begin{array}{c}\text { Standard } \\
\text { load } \\
{[\mathbf{k N}]}\end{array}$} & \multicolumn{4}{|c|}{ Applied load [kN] at moisture W [\%] } \\
\cline { 3 - 6 } & & \multicolumn{2}{|c|}{$\mathbf{W}_{\text {opt }}: \mathbf{1 . 0} \%$} & $\mathbf{W}_{\text {opt }}$ & $\mathbf{W}_{\text {opt }}:+\mathbf{1 . 0} \%$ \\
\hline 0 & & 0 & 0 & 0 & 0 \\
\hline 0.5 & & 0.49 & 0 & 1.32 & 1.1 \\
\hline 1 & & 0.97 & 0 & 3.33 & 2.86 \\
\hline 1.5 & & 1.68 & 0 & 6 & 4.56 \\
\hline 2 & & 3.02 & 0 & 8.86 & 7.22 \\
\hline 2.5 & $\mathbf{1 3 . 2}$ & $\mathbf{4 . 4 5}$ & $\mathbf{0 . 2}$ & $\mathbf{1 1 . 8 2}$ & $\mathbf{9 . 8 7}$ \\
\hline 3 & & 5.8 & 3 & 15.3 & 13.56 \\
\hline 3.5 & & 9.31 & 5.8 & 18.76 & 16.3 \\
\hline 4 & & 10.36 & 8.5 & 21.1 & 19.85 \\
\hline 4.5 & & 11.22 & 11.4 & 24 & 21.36 \\
\hline $\mathbf{5}$ & $\mathbf{2 0}$ & $\mathbf{1 4 . 3 8}$ & $\mathbf{1 4 . 3 8}$ & $\mathbf{2 7 . 1}$ & $\mathbf{2 4 . 3}$ \\
\hline 7.5 & & 28.25 & 28.25 & 41.2 & 38.9 \\
\hline 10 & & 40.56 & 40.56 & 50 & 46.5 \\
\hline \multicolumn{2}{|l|}{ IBI $_{2,5}$} & & $\mathbf{2}$ & $\mathbf{9 0}$ & $\mathbf{7 5}$ \\
\hline \multicolumn{2}{|l|}{ IBI $_{5,0}$} & & $\mathbf{7 0}$ & $\mathbf{1 3 5}$ & $\mathbf{1 2 0}$ \\
\hline
\end{tabular}

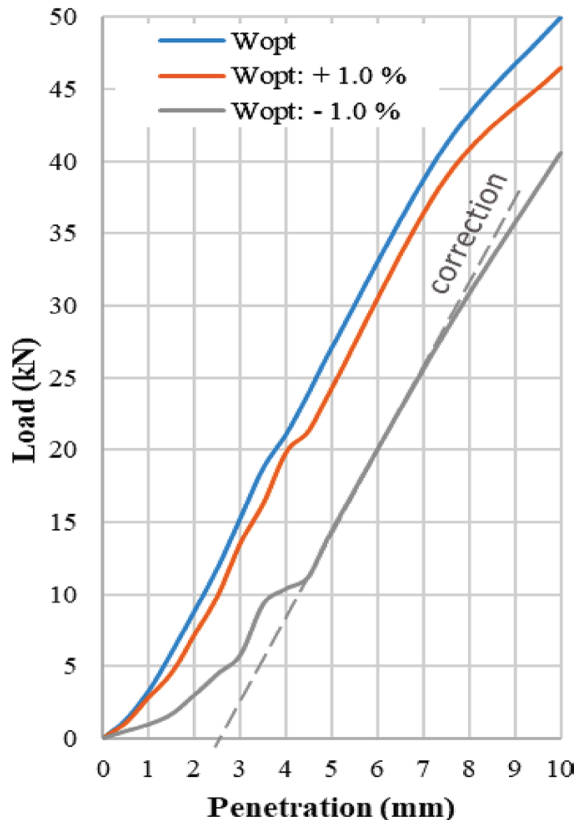

Fig. 11 Immediate bearing index - laboratory procedure

\section{CONCLUSION}

From the perspective of the time-consuming realization of the base layer, the fastest method is to make an unbound layer of mechanically reinforced aggregates versus a cement bounded mixture. In the case of an economic comparison, it is necessary to take into account several factors, i.e., the materials used, the construction machines, the technological processes of the production and processing of the mixtures, the thickness of the layers, the treatment of the finished layers (spraying, coating, watering), and the creation of joints and related activities.

When comparing the parameters of the mixtures, it should be noted that a laboratory tries to simulate "ideal" conditions, but in a real environment a large number of factors can be affected at irregular intervals. Knowledge and practical experience show that although the results of the MSK laboratory tests are in accordance with the technical regulations, the immediate bearing index (IBI) is sometimes not achieved on the site. Mixtures with the optimum and higher moisture levels meet the requirements of the standard at minimum IBI values of $+35 \%$ and $+20 \%$, respectively. It is therefore assumed that if the prescribed technological procedures are followed, this condition will also be fulfilled at the construction site.

The unbound base layers mentioned were successfully used in the pavement structures on significant roads and traffic areas within Slovakia, e.g., the R1 expressway, the Trnava industrial park, the Jaguar Land Rover Nitra industrial park, the parking and tertiary communications of Volkswagen Bratislava, the relocation of road II/520 Nová Bystrica-Oravská Lesná, the R3 bypass of Trstená, etc. These represent traffic areas with higher traffic loads, where the justification for using the MSK mixture in the road construction was confirmed. The quality of the MSK mixture is achieved by the technology of the production of the aggregate mixture, which must be designed with the strict requirements of the standards and technical regulations.

\section{Acknowledgments}

This paper was created with the support of VEGA Grant No. 1/0501/17 and the University Science Park of the Slovak University of Technology in Bratislava, ITMS: 26240220084 and ITMS:313021D243 projects. 


\section{REFERENCES}

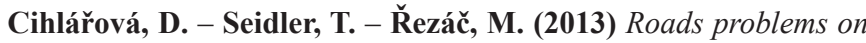
undermined areas in the Moravian-Silesian region. In: Conference proceedings of 3rd International Conference on Civil Engineering and Transportation, ICCET 2013. Kunming, China: Dec 14-15, 2013. Vols. 505-506, pp. 477-480, ISSN: 16609336, ISBN: 978-303835006-4.

Červená I. (2018) Mechanically reinforced aggregates in road construction - design of a mixture for the I. to III. traffic load class. Diploma thesis. Supervisor: Silvia Capayova, Department of Transportation Engineering, Faculty of Civil Engineering, Slovak University of Technology in Bratislava, 71 pp.

Chandra, S. (2004) Implications of Using Recycled Construction and Demolition Waste as Aggregate in Concrete. Session Lead Paper. Proceedings of the International Conference on Sustainable Waste Management and Recycling, Kingston University, London, 14-15 Sept. 2004. In: Limbachiya, M.C. and Roberts, J.J., Eds., Sustainable Waste Management and Recycling: Challenges and Opportunities. Vol. 2-Construction Demolition Waste, Thomas Telford Publishing, London, pp. 105-114.

Qiu-Yi L. (2005) The influence of a particle shape correcting technique in properties of recycled coarse aggregate. Material Science and Technology, Vol. 13, No. 6, pp. 579-581, ISSN: 10050299.

Hirokazu, Sh. - Hisashi, T. - Ryuji, M. - Yoshikuni, Y. (2005) An advanced concrete recycling technology and its applicability assessment through input-output analysis. Journal of Advanced Concrete Technology, Vol. 3, No. 1, pp. 53-67, online ISSN: 1347-3913, https://doi.org/10.3151/jact.3.53.

Moravčík, M. - Bujňáková, P. - Krkoška, L. - Koteš, P. (2016) Diagnostic assessment of one of the first generation of prestressed concrete bridges in Slovakia. In: 9th International Conference on Bridges in the Danube Basin, BDB 2016, Zilina, Slovakia, Sept. 30-Oct. 1 2016, Code 131730, Vol. 156, 2016, pp. 257-263, https://doi.org/10.1016/j.proeng.2016.08.295.
Stehlík D. (2015) Waste Building Materials to Pavement of Roads. Recycling 2015. ARSM, Brno, Czech Republic, pp. 4 - 11, Publisher: Brno University of Technology, ISBN 978-80-214-5141-4.

Ministry of the Interior of the Slovak Republic (2019) Total number of registered vehicles in the SR, available on: https://www. minv.sk/?celkovy-pocet-evidovanych-vozidiel-v-sr.

STN EN 13242+A1 (2008) Aggregates for unbound and hydraulically bound materials for use in civil engineering work and road construction, Slovak Office of Standards.

STN EN 13286-1 (2004) Unbound and hydraulically bound mixtures. Part 1: Test methods for the determination of the laboratory reference density and water content. Introduction, general requirements and sampling, Slovak Office of Standards.

STN EN 13286-2 (2013) Unbound and hydraulically bound mixtures. Part 2: Test methods for laboratory reference density and water content. Proctor compaction, Slovak Office of Standards.

STN EN 13286-47 (2012) Unbound and hydraulically bound mixtures. Part 47: Test method for the determination of California bearing ratio, immediate bearing index and linear swelling, Slovak Office of Standards.

KLK 1/2012 (2012) Catalogue sheets of aggregates, Ministry of Transport, Construction and Regional Development of the Slovak Republic.

TKP 5 (2014) Technical qualitative requirements, Base layers, Ministry of Transport, Construction and Regional Development of the Slovak Republic. 